\title{
Immunologic Tolerance in Lymphatic Filariasis \\ Diminished Parasite-specific T and B Lymphocyte Precursor Frequency in the Microfilaremic State
}

\author{
Christopher L. King, " V. Kumaraswami," Robert W. Poindexter," Suman Kumari," Kunthala Jayaraman," David W. Alling," \\ Eric A. Ottesen, * and Thomas B. Nutman* \\ ${ }^{*}$ Laboratory of Parasitic Diseases, National Institutes of Health, Bethesda, Maryland 20892; ${ }^{\ddagger}$ Tuberculosis Research Center, Madras, \\ India; ${ }^{\S}$ Department of Biotechnology, Anna University, Guindy, Madras, India; and "National Institute of Allergy and Infectious \\ Diseases, Bethesda, Maryland 20892
}

\section{Abstract}

To explore the mechanisms of antigen-specific immune unresponsiveness seen in microfilaremic patients with bancroftian filariasis, $T$ and $B$ cell precursor frequency analysis was performed using PBMC from individuals with either asymptomatic microfilaremia (MF, $n=7$ ) or chronic lymphatic obstruction $(\mathrm{CP}, n=20)$. Highly purified CD3 + cells were partially reconstituted with adherent cells and their proliferative response to parasite antigens determined in cultures of $T$ cells by limiting dilution analysis. A filter immunoplaque assay also assessed the frequency of both total and parasite-specific Igproducing B cells. While the lymphocyte proliferation to mitogens and to a nonparasite antigen (Streptolysin-O, [SLO]) were similar in all groups of patients, the frequency of parasite-specific CD3 + $\mathbf{T}$ cells was significantly lower (geometric mean [GM], 1/3,757) in MF patients when compared to that in CP patients (GM 1/1,513; $P<0.001)$. Similarly, the proportion of lymphocytes producing parasite-specific IgE or IgG was signifcantly lower in MF patients (IgE mean, 0.2\%; IgG mean, 0.33\%) compared with CP patients (IgE mean, 3.2\%; IgG mean, 1.76\%; $P<0.05$ for both comparisons). These observations imply that low numbers of parasite-specific $T$ and $B$ lymphocytes may be partially responsible for the severely diminished capacity of lymphocytes from patients with MF to produce parasite-specific antibody and to proliferate to parasite antigen in vitro. Such differences in parasite-specific lymphocyte responses suggest that tolerance by clonal anergy may be a critical mechanism for maintaining the microfilaremic state. ( $J$. Clin. Invest. 1992. 89:1403-1410.) Key words: limiting dilution analysis • ELISPOT assay • IgE

\section{Introduction}

The human lymphatic filariases, estimated to affect about 100 million people worldwide, are persistent infections that induce a breadth of host immune responses implicated in the pathogenesis of the different clinical manifestations of this infection

Address correspondence and reprint requests to Dr. Christopher $\mathrm{L}$ King, c/o Dr. Thomas Nutman, Laboratory of Parasitic Diseases, Building 4, Room 126, National Institutes of Health, Bethesda, MD 20892.

The present address of Dr. Christopher L. King is Case Western Reserve University, Division of Geographic Medicine, School of Medicine, 2109 Adelbert Road, Cleveland, OH 44106.

Received for publication 22 February 1991 and in revised form 31 October 1991.

The Journal of Clinical Investigation, Inc.

Volume 89, May 1992, 1403-1410
(1). These responses in both brugian and bancroftian filariasis include: (a) intermittent lymphangitis and lymphadenitis ("filarial fevers") that can lead to chronic lymphatic obstruction; (b) the syndrome of tropical pulmonary eosinophilia; and (c) a condition in which individuals are asymptomatic, but have persistent microfilaremia (2). It has been postulated that these different clinical responses reflect the nature of the host immune response to filarial infection $(2,3)$.

The most common manifestation of lymphatic filarial infections, that of asymptomatic microfilaremia, has been suggested (3-5) to result from selective immune defects in the host response to the parasite that allows the microfilariae to persist in the circulation, thereby ensuring continued transmission of the parasite to the mosquito vector. The 'impaired' immune response in microfilaremic individuals (MF $)^{1}$ is defined by generally low serum levels of parasite-specific antibodies $(5,6)$, failure of antigen-specific $B$ cells to respond to parasite antigens in vitro (7), and impaired $\mathrm{T}$ lymphocyte function in response to parasite antigens in vitro $(4,5,8)$. These diminished immune responses are parasite antigen specific in that $B$ and $T$ cell responses to nonparasite antigen and mitogens remain normal.

The mechanisms underlying this parasite-specific immune hyporesponsiveness have been postulated to involve adherent suppressor cells (presumably monocytes), serum suppressive factors (9), or suppressor T lymphocytes (10). Alternatively, the immunologically hyporesponsive microfilaremic state may result from a diminished number of parasite antigen-responsive lymphocytes (7) as a consequence of perinatal sensitization or tolerization to the parasite. The present study examines this hypothesis by comparing the precursor frequency of parasite antigen-specific $\mathrm{T}$ and $\mathrm{B}$ lymphocytes in patients with asymptomatic microfilaremia and in amicrofilaremic individuals with chronic lymphatic obstruction.

\section{Methods}

Study population. 27 adult volunteers (Table I) living in the area of Madras, India, where bancroftian filariasis is endemic, were studied. Each individual provided a clinical history, underwent a physical examination, had blood examined for circulating microfilariae and served as a donor of PBMCs. Circulating microfilariae were enumerated by polycarbonate filter (Nuclepore Corp., Pleasanton, CA) filtration of $3 \mathrm{ml}$ of nocturnally collected blood (11). Additionally, five normal North American individuals (three females and two males) between 30 and 41 yr old were studied as controls.

Antigens and mitogens. Brugia malayi filarial antigen (BMA) was prepared as the saline extract of adult-stage parasites (6). Pokeweed

1. Abbreviations used in this paper: BMA, Brugia malayi filarial antigen; CP, chronic lymphatic obstruction; MF, microfilaremia; SLO, streptolysin-O. 
mitogen (PWM; Gibco, Grand Island, NY) and streptolysin-O (SLO; Difco Laboratories, Inc., Detroit, MI) were used as controls.

Isolation of PBMC. All studies were performed on fresh PBMCs obtained from heparinized venous blood and separated by Ficoll-diatrizoate gradient centrifugation (12).

Enzyme-linked immunosorbent assay (ELISA) for parasite-specific $\operatorname{Ig} G$ and IgE. Parasite-specific IgG was performed exactly as described previously (7). For the parasite-specific IgE assay, flat-bottomed Immulon 4 microtiter plates (Dynatech Laboratories, Inc., Alexandria, VA) were coated with $10 \mu \mathrm{g} / \mathrm{ml}$ of BMA in PBS at $\mathrm{pH} 9.6$. The plates were washed in PBS containing 0.05\% Tween-20 (Sigma Chemical Co., St. Louis, MO) and blocked with PBS containing 5\% BSA for $1 \mathrm{~h}$. After further washes, protein G (Genex Co., Gaithersburg, MD) absorbed $\left(4^{\circ} \mathrm{C}\right.$ for $\left.4 \mathrm{~h}\right)$ serum sample or IgE standards were added and incubated at $4^{\circ} \mathrm{C}$ overnight. The wells were washed as before and incubated with $0.5 \mu \mathrm{g} / \mathrm{ml}$ of a anti-human IgE monoclonal antibody (7.12; obtained from Dr. Andrew Saxon, UCLA Medical Center, and described previously [13]). After a 2-h incubation at $37^{\circ} \mathrm{C}$, the wells were washed and $0.2 \mu \mathrm{g} / \mathrm{ml}$ of biotinylated goat anti-mouse IgG (Jackson Immunoresearch Labs., Inc., Malvern, PA) was added and again incubated at $37^{\circ} \mathrm{C}$ for $2 \mathrm{~h}$. After washing the wells, streptavidin-alkaline phosphatase (Jackson Immunoresearch Inc.) was added for $1 \mathrm{~h}$ at RT. Wells were again washed and p-nitrophenyl phosphate substrate (Sigma Chemical Co.) was added. Subsequent development of color was measured at $410 \mathrm{~nm}$, using an automated microplate ELISA reader (Dynatech Labs., Inc., Springfield, VA).

Proliferation assays. PBMC $\left(10^{6} / \mathrm{ml}\right)$ were cultured in round-bottom microtiter plates in $0.2 \mathrm{ml}$ of C-RPMI 1640 supplemented with gentamicin $(80 \mu \mathrm{g} / \mathrm{ml})$, Hepes $(25 \mathrm{mM})$ and $10 \%$ human $\mathrm{AB}$ serum. To the wells were added media, BMA, SLO, or PWM. All cultures were performed in quadruplicate or sextuplicate and maintained in a humidified atmosphere with $5 \% \mathrm{CO}_{2}$ at $37^{\circ} \mathrm{C}$. After $6 \mathrm{~d}, 20 \mu \mathrm{l}$ of C-RPMI containing $1 \mu \mathrm{Ci}\left[{ }^{3} \mathrm{H}\right]$ thymidine (New England Nuclear, Boston, MA) was added to the cultures that were then incubated for an additional 16 $h$ before the cells were collected on glass filters with a cell harvester (Skatron Inc., Sterling, VA). The incorporation of thymidine was measured by liquid scintillation spectroscopy (Pharmacia LKB Nuclear, Inc., Uppsala Sweden). Data are expressed as the stimulation in$\operatorname{dex}(\mathrm{SI})$.

Parasite-specific $T$ cell precursor assay. The frequency of parasitespecific $\mathrm{T}$ lymphocytes was determined by limiting dilution analysis after cell stimulation by BMA $(5 \mu \mathrm{g} / \mathrm{ml})$ in the presence of autologous adherent cells. Round-bottomed 96-well microtiter plates were initially coated with adherent or accessory cells by incubating the wells with 5,000 PBMC $(100 \mu l)$ in RPMI with 5\% human AB serum in a humidified atmosphere of $5 \% \mathrm{CO}_{2}$ at $37^{\circ} \mathrm{C}$ for $1 \mathrm{~h}$ before removing nonadherent cells. $\mathrm{T}$ lymphocytes were purified by negative selection (One Lambda, Inc., Los Angeles, CA) to yield enriched T cell preparations $>94 \%$ CD3+. T cells were added to microtiter plates containing adherent cells in limiting dilution with 42 replicate cultures set up at each cell concentration $\left(10^{3}, 5 \times 10^{3}, 10^{4}, 5 \times 10^{4}\right.$ cells/culture $)$ and incubated at $37^{\circ} \mathrm{C}$ for a total of $7 \mathrm{~d}$. 36 wells received BMA; the other cultures contained media alone. From the 36 replicate BMA-stimulated cultures at each $\mathrm{T}$ cell concentration, only those were scored as positive in which the $\left[{ }^{3} \mathrm{H}\right]$ thymidine incorporation exceeded the mean of the six unstimulated cultures at the corresponding cell number by $>3$ standard deviations. At each cell concentration, parallel cultures were stimulated with PWM, a mitogen whose proliferation kinetics parallel those of most soluble antigens.

Filter Spot-ELISA assay. This assay has been described in detail for detection of B cells secreting polyclonal IgE (14). The assay was adapted in the present study to measure the number of parasite-specific B cells secreting IgE and IgG antibody, as well as B cells secreting polyclonal IgG. Briefly, nitrocellulose-bottomed 96-well Millititer HA plates (Millipore Corp., Bedford, MA) were coated with the appropriate antibody or antigen in PBS (pH 9.6) overnight at $4^{\circ} \mathrm{C}$ in a humidified chamber. The plates were subsequently washed and blocked with PBS-5\% BSA for $1 \mathrm{~h}$ at $37^{\circ} \mathrm{C}$ and washed again before adding known concentrations of PBMC (beginning at $10^{6}$ cells) to each well in $0.1 \mathrm{ml}$ of RPMI with $10 \%$ FCS. Routinely, samples were run in quadruplicate, serially diluted (twofold) from the initial concentration at least six times, and were incubated undisturbed either for $4 \mathrm{~h}$ or overnight at $37^{\circ} \mathrm{C}$ in a humidified $\mathrm{CO}_{2}$ incubator. At the completion of the cell incubation stage, the plates were washed six times in PBS with $0.25 \%$ Tween-20 (PBS-T), and the appropriate antibodies (see below) in PBST containing 1\% BSA (PBS-BT; Sigma Chemical Co., St. Louis, MO) were added to each well, incubated at $37^{\circ} \mathrm{C}$ for $2 \mathrm{~h}$, and washed six times in PBS-T before alkaline-phosphatase induced development with BCIP/NBT substrate solution (Kirkegaard and Perry Labs., Inc., Gaithersburg, MD). Positive reactions produced insoluble precipitates recognizable as blue spots (each spot representing a single immunoglobulin-producing B lymphocyte). The plates were then dried, and the blue spots were enumerated using a dissecting microscope. For the IgE assays, since the second antibody (mouse monoclonal anti-human IgG) was not directly conjugated to alkaline phosphatase, there was an additional step of adding phosphatase-conjugated rabbit anti-mouse IgG (Jackson ImmunoResearch Labs., Inc.) to each well, followed by incubation again at $37^{\circ} \mathrm{C}$ for $2 \mathrm{~h}$, and six washes in PBS-T before development.

The specific antibodies used for coating the plates were $5 \mu \mathrm{g} / \mathrm{ml}$ of affinity-purified anti-human IgE (Kirkegaard and Perry Labs., Inc.), or $5 \mu \mathrm{g} / \mathrm{ml}$ of goat anti-human IgG (Jackson ImmunoResearch Labs., Inc.) for the polyclonal assays; for the parasite-specific antibody assays the plates were coated with BMA antigen $(20 \mu \mathrm{g} / \mathrm{ml})$. The second antibodies used for both the polyclonal and parasite-specific assays were either a monoclonal anti-human IgE antibody (4.15 at $2 \mu \mathrm{g} / \mathrm{ml}$, obtained from Dr. Andrew Saxon and described previously [13]), or alkaline phosphatase-conjugated rabbit anti-human IgG (Jackson ImmunoResearch Labs., Inc.).

The specificity of the filarial antigen-specific ELISPOT assays was demonstrated in that an IgE-producing myeloma cell line (U266), an EBV-transformed IgG-secreting B cell clone, and cells from a hyperIgE patient with greater than $1 \%$ B cells producing $\operatorname{IgE}(15)$, failed to produce any spots in these assays.

Estimates of $B$ cell proportion in PBMC. The proportion of B cells in the PBMC was determined by modification of a method described elsewhere in detail (16) which included the following steps: (a) fixing 20 $\mu$ l PBMC $\left(5 \times 10^{5}\right.$ cells $\left./ \mathrm{ml}\right)$ to glass slides pretreated with $5 \mu \mathrm{g} / \mathrm{ml}$ of poly-L-lysine, $M_{\mathrm{r}}>70 \mathrm{~K}$ (Sigma Co., St. Louis, MO) for $30 \mathrm{~min}$ at RT; (b) gently washing slides with Tris-Hanks' solution containing $0.2 \%$ human serum albumin (TH-HSA) and fixing cells for $5 \mathrm{~min}$ at RT with $1 \%$ paraformaldehyde in PBS; $(c)$ incubating the slides with $20 \mu \mathrm{l}$ of 1:10 dilution of unconjugated mouse anti-human CD 19 antibody (Becton Dickinson Immunocytometry Sys., Mountain View, CA) for 20 min at RT after washing the slides in TH-HSA; $(d)$ washing the slides again and incubating with $20 \mu \mathrm{l}$ of a 1:20 dilution alkaline phosphatase conjugated rabbit anti-mouse IgG (Jackson Immunoresearch Labs., Inc.); (e) rewashing the slides and incubating with $20 \mu \mathrm{l}$ of a 1:20 dilution alkaline phosphatase conjugated goat anti-rabbit IgG (Jackson Immunoresearch Labs., Inc.); $(f)$ developing the slides with alkaline phosphatase substrate (SK-5300; Vector Labs., Inc., Burlingame, $\mathrm{CA}$ ); and $(g)$ counterstaining with $1 \%$ neutral red before counting under the light microscope. Slides were read immediately for best results with B cells observed to have a dark precipitate around their borders.

Data analysis. Because the response to dilution of the $\mathrm{CD}^{+}$, parasite-specific $\mathrm{T}$ cells in the limiting dilution assay was frequently nonlinear on a semilog plot, and hence, not consistent with a single hit Poisson model, the hit number of the assay data for each donor was estimated (reference $17, \mathrm{pp} .608-609$ ) and found to average $0.32 \pm 0.04$ (SE). Thus, the traditional single hit model was abandoned, and instead, we assumed that hit number varies with donor; accordingly, the expected number of positive wells at the ith dilution of the jth donor's cells was taken to be $n_{\mathrm{j}} 10^{-\mathrm{a} i \mathrm{j})}$ where $n_{\mathrm{j}}$ is the true number of specific T cells at the lowest dilution of the series, $i=0,1,2,3$ and $c(\mathrm{i}, \mathrm{j})=d_{\mathrm{i}} h_{\mathrm{j}}$ where $d_{\mathrm{i}}$ is the ith dilution factor and $h_{\mathrm{j}}$ is the hit number for the jth 
donor. The parameter $n_{\mathrm{j}}$ was estimated by least squares using the expression $n_{\mathrm{j}}=\sum_{\mathrm{i}} p_{\mathrm{ij}} \hat{c}(\mathrm{i}, \mathrm{j}) / \sum_{\mathrm{i}} \hat{c}(\mathrm{i}, \mathrm{j})^{2}$ where $p_{\mathrm{ij}}$ is the number of positive wells at ith dilution of the jth donor's cells and $\hat{c}(\mathrm{i}, \mathrm{j})$ is an estimate of $c(i, j)$ based on the hit number $\hat{h}_{j}$ suggests that another cell type is interfering with the action of the antigen-specific $T$ cell, but that such interference is progressively weakened as the dilution is increased.

For comparison, the frequency of antigen-reactive cells was determined by conventional limiting dilution analysis according to Lefkovits and Waldman and modified by Taswell $(18,19)$.

Means were compared using student's $t$ test with logarithmically transformed data. Correlation coefficients were determined based upon simple linear regression of logarithmically transformed data.

\section{Results}

Clinical findings. 20 individuals with chronic lymphatic obstruction (CP) and 7 individuals with asymptomatic microfilaremia (MF) were studied (Table I). None of the patients with microfilaremia had symptoms associated with filariasis, whereas all patients with $\mathrm{CP}$ had evidence of chronic lymphatic obstruction in one or more limbs, and 11 of $20 \mathrm{CP}$ patients had a recent history (within the past $6 \mathrm{mo}$ ) of acute lymphangitis, lymphadenitis, and fevers, a complex commonly referred to as filarial fevers. The CP patients were of both sexes and signifi-

Table I. Patient Population

\begin{tabular}{|c|c|c|c|c|c|c|}
\hline \multirow[b]{2}{*}{ Diagnosis } & \multirow[b]{2}{*}{ Age/sex } & \multirow[b]{2}{*}{ Microfilariae } & \multicolumn{2}{|c|}{$\mathrm{SI}^{*}$} & \multicolumn{2}{|c|}{ Antifilarial antibody } \\
\hline & & & BMA & SLO & IgG & IgE \\
\hline & & No./ml & & & $U / m l$ & $\mu g / m l$ \\
\hline \multicolumn{7}{|l|}{ Recent filarial fevers ${ }^{\ddagger}$} \\
\hline $\mathrm{CP}$ & $25 / \mathrm{M}$ & 0 & ND & ND & 1202 & 151 \\
\hline $\mathrm{CP}$ & $53 / \mathrm{M}$ & 0 & ND & ND & 202 & 12 \\
\hline $\mathrm{CP}$ & $28 / \mathrm{M}$ & 0 & 60.9 & 28.0 & 398 & 54 \\
\hline $\mathrm{CP}$ & $33 / \mathrm{F}$ & 0 & 50.4 & 1.9 & 710 & 1303 \\
\hline $\mathrm{CP}$ & $35 / \mathrm{M}$ & 0 & ND & ND & 1894 & 110 \\
\hline $\mathrm{CP}$ & $50 / \mathrm{F}$ & 0 & 17.5 & 38.9 & 321 & $<10$ \\
\hline $\mathrm{CP}$ & $38 / \mathrm{F}$ & 0 & ND & ND & 415 & 81 \\
\hline $\mathrm{CP}$ & $40 / F$ & 0 & 78.5 & 73.0 & 3039 & 121 \\
\hline $\mathrm{CP}$ & $50 / \mathrm{M}$ & 0 & 56.8 & 1.2 & 492 & $<10$ \\
\hline $\mathrm{CP}$ & $35 / \mathrm{M}$ & 0 & 24.5 & 2.8 & 612 & 23 \\
\hline $\mathrm{CP}$ & $48 / F$ & 0 & $\underline{56.8}$ & 57.2 & 170 & $<10$ \\
\hline Geometric means $(+F F)$ & & & 44.3 & 11.6 & 584 & 48 \\
\hline \multicolumn{7}{|l|}{ No filarial fevers } \\
\hline $\mathrm{CP}$ & $45 / \mathrm{M}$ & 0 & ND & ND & 464 & 1143 \\
\hline $\mathrm{CP}$ & $60 / F$ & 0 & 5.1 & 19.2 & 440 & 81 \\
\hline $\mathrm{CP}$ & $45 / F$ & 0 & ND & ND & 808 & 72 \\
\hline $\mathrm{CP}$ & $25 / F$ & 0 & 3.7 & 4.7 & 1016 & 322 \\
\hline $\mathrm{CP}$ & $55 / \mathrm{M}$ & 0 & 4.3 & 84.1 & 84 & $<10$ \\
\hline $\mathrm{CP}$ & $25 / \mathrm{M}$ & 0 & 21.6 & 55.8 & 12190 & 313 \\
\hline $\mathrm{CP}$ & $61 / M$ & 0 & 13.4 & 3.8 & 537 & 81 \\
\hline $\mathrm{CP}$ & $22 / \mathrm{M}$ & 0 & 5.1 & 2.0 & 616 & 43 \\
\hline $\mathrm{CP}$ & $30 / F$ & 0 & 7.6 & 48.2 & 187 & $\leq 10$ \\
\hline Geometric means (-FF) & & & 7.1 & 14.8 & 603 & 85 \\
\hline Geometric means (all CP) & & & 17.8 & 13.2 & 590 & 62 \\
\hline MF & $28 / \mathrm{M}$ & 1200 & 2.7 & 22.3 & 273 & 43 \\
\hline MF & $27 / \mathrm{M}$ & 96 & 1.8 & 4.0 & 640 & 22 \\
\hline MF & $35 / \mathrm{M}$ & 450 & 2.1 & 7.8 & 654 & 28 \\
\hline MF & $28 / \mathrm{M}$ & 550 & 1.8 & 2.3 & 1192 & 22 \\
\hline MF & $28 / \mathrm{M}$ & 400 & 2.5 & 15.6 & 1337 & 33 \\
\hline MF & $22 / \mathrm{M}$ & 360 & 1.5 & 107.0 & 808 & 58 \\
\hline MF & $24 / M$ & 740 & 1.9 & 32.1 & 357 & $<10$ \\
\hline \multicolumn{7}{|l|}{ Geometric means } \\
\hline$(+\mathrm{MF})$ & & 437 & $2^{\S}$ & 13.6 & 659 & 27 \\
\hline
\end{tabular}

* Stimulation index of lymphocyte cultures stimulated with $5 \mu \mathrm{g} / \mathrm{ml}$ of BMA.

‡Within past $6 \mathrm{mo}$.

${ }^{\S} P<0.001$, as compared to $\mathrm{CP}$. 
cantly older (median age 39) than the MF patients, (median age 28) all of whom were males.

Antibody and lymphocytes proliferation responses. Geometric mean serum antifilarial IgG and IgE antibody levels were similar between MF and CP patients. When the percentage of filaria-specific IgE was compared between the two groups, patients with $\mathrm{CP}$ tended to have a higher proportion of filaria-specific serum IgE (4.1\%, range 0-9.7\%) than did the MF individuals $(1.4 \%$, range $0-3.5 \% ; P=0.052)$. There was no difference in the ratio of filaria-specific IgG to total IgG (CP, 0.030 vs. MF, 0.041); these values, of course, cannot describe the actual percentage of filarial-specific serum IgG levels because the antifilarial IgG levels were measured only in units (Table I).

A striking difference between the immune responses of $\mathrm{CP}$ and MF groups was the marked heterogeneity seen in both $\mathrm{T}$ cell proliferation and serum anti-filarial antibody levels among the CP patients. This heterogeneity may reflect the fact that some in the CP group were still actively infected with filariasis, while others probably showed only the sequelae of past infection. To distinguish between these possibilities, we tested for circulating filarial antigen in the plasma of each study subject and found no association between the levels of $(a)$ circulating antigen and serum antifilarial antibodies levels; $(b)$ the magnitude of $\mathrm{T}$ cell proliferation to parasite antigen; or $(c)$ with the frequency of parasite-specific $T$ cells (data not shown). When the CP patients were segregated on the basis of a history of recent filarial fevers (i.e., acute lymphangitis within the past 6 $\mathrm{mo}$ ), those with positive histories were found to have significantly greater proliferative responses to parasite antigen $(P$ $=0.001$; Table I) than those without a recent episode of adenolymphangitis. There was, however, no relationship between serum antibody levels and the history of recent filarial fever episodes (Table I).

Lymphocyte responses to parasite antigen were strikingly different in the two patient groups (Table I). Among the MF patients, none had SI greater than 3, whereas lymphocytes from all CP patients proliferated to parasite antigen (geometric mean SI = 17.5), the difference between the two groups being highly significant $(P<0.001)$. When a nonfilarial antigen (SLO) was used to stimulate lymphocyte cultures, both MF and CP patients responded similarly (Table I).

Frequency of parasite-specific T lymphocytes. Because peak lymphocyte proliferation for most individuals studied occurred at a parasite antigen concentration of $5 \mu \mathrm{g} / \mathrm{ml}$ (data not shown), this antigen concentration was used for stimulating $\mathrm{T}$ cells in the limiting dilution experiments. Fig. 1 shows the semilogarithmic plot for the data from four representative patients (two MF, solid circle and square, and two $\mathrm{CP}$, open circle and triangle). If one cell of one cell type were responsible for the proliferation response observed (e.g., a single hit phenomenon), then the plots shown in Fig. 1 should be linear. For most individuals studied this relationship was nonlinear (5 of $7 \mathrm{MF}$ and 14 of $20 \mathrm{CP}$ ) and were of the convex shape represented by three of four individuals shown in Fig. 1. The convex-shaped curves indicate that the percentage of total $T$ cells that are antigen-reactive appears to be less at greater $T$ cell concentrations than at lower $T$ cell numbers. The frequency of parasite-antigen-reactive $T$ cells was markedly lower among the MF patients shown in Fig. 1 (patient 32, Fo $=1 / 5,495$, and patient 20, Fo $=1 / 4,673$ ) compared with $\mathrm{CP}$ individuals (patient 16, Fo $=1 / 1,441$ and patient $10, \mathrm{Fo}=1 / 1,370)$. This reduction in the frequency of antigen-reactive $T$ cells persisted when all MF patients were combined (geometric mean $[\mathrm{GM}]=1 / 3,757$ ) in

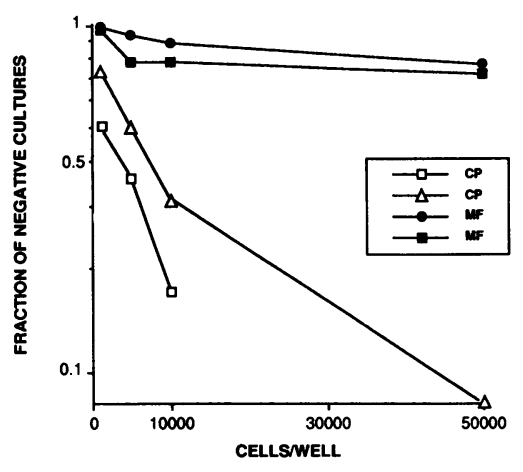

Figure 1. Limiting dilution analysis of the $T$ cell response to parasite antigens in representative patients with microfilaremia (solid points) and chronic pathology (open points). Patient 32 (circle), Fo $=1 / 5,495$; patient 20 (solid square) Fo $=1 / 4,673$; patient 16 (open triangle) Fo $=1 / 1,441 ;$ and patient 10 (open square) $\mathrm{Fo}=1 / 1,370$. The fraction of negative wells at $50,000 \mathrm{~T}$ cells/well was not shown for patient 10 ( $0 \%$ negative cultures).

contrast to $\mathrm{CP}$ patients $(\mathrm{GM}=1 / 1,513, P<0.001$; Fig. 2$)$. As expected, normal unexposed individuals had rare antigen-responsive cells, with a geometric mean that was significantly lower than that of the CP group $(P<0.001)$, but not statistically different from that of the MF patients. Interestingly, in 21 patients for whom proliferation data were available (Table I), the magnitude of the proliferation response by PBMC to parasite antigens correlated closely with the frequency of parasiteantigen-responsive T cells $(r=0.83, P<0.001)$.

As noted above, patients with MF were significantly younger than $\mathrm{CP}$ patients in this particular study population. To determine whether this age difference might affect the difference in the Fo of antigen-reactive lymphocytes (ARL) between the CP and MF groups, a subset of nine CP patients with the same age distribution as the MF patients was examined. This subset of CP patients had Fo of ARL that was not significantly different from that of all $20 \mathrm{CP}$ patients $(\mathrm{GM}=1 / 1,430)$. It was, as expected, also significantly greater than that of $\mathrm{MF}$ patients $(P=0.03)$.

Frequency of total and parasite-specific immunoglobulinsecreting $B$ cells. To determine directly whether patients with MF also had decreased numbers of parasite-specific immunoglobulin-secreting B cells compared with CP patients, the frequencies of both total and parasite-specific IgE and IgG-secret-

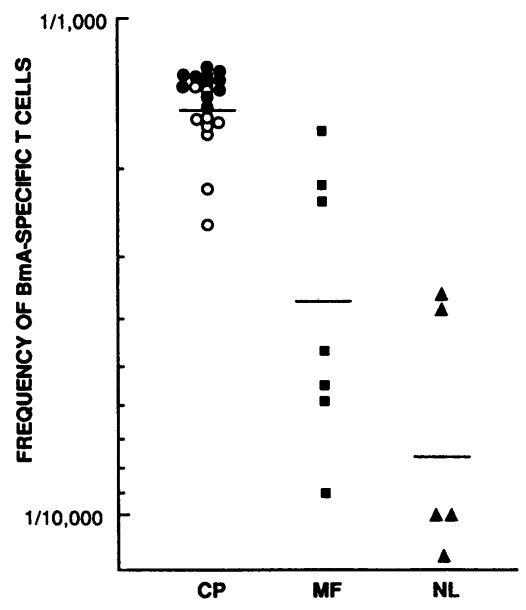

Figure 2. The frequency of filaria-specific $T$ lymphocytes in patients with lymphatic filariasis and normal individuals. Values are expressed as the frequency of parasite-antigen-responsive $T$ lymphocytes and the horizontal lines represent the geometric means. Each point represents one individual with chronic lymphatic obstruction (CP, circles), asymptomatic microfilaremia (MF, squares), or no filarial

infections (NL, triangles). Open circles among $\mathrm{CP}$ patients represent individuals not having histories of filarial fevers during the 6 mo before the time of study. 
ing B lymphocytes were determined for the two groups (Fig. 3). The frequency of polyclonal IgE-secreting B cells was actually higher among individuals with MF than among the $\mathrm{CP}$ patients (Fig. 3, $P=0.01$ ), whereas the frequency of polyclonal IgG-secreting B cells was similar in the two groups. In contrast, only one of seven patients with MF had detectable parasite-specific IgE-secreting B cells, compared with 13 of 20 patients with CP (Fisher's exact test; $P<0.01$ ). Similarly, the frequency of parasite-specific IgG-secreting lymphocytes also appeared diminished among MF patients, compared with individuals with $\mathrm{CP}$, though this difference did not reach statistical significance (Fig. 3; $P=0.052$ ). However, when the data were examined as the percent of the IgE- or IgG-secreting B cells that were producing filaria-specific antibody (Fig. 4), the proportion of the total number of cells secreting parasite-specific antibody was seen to be significantly lower $(P<0.01)$ in MF patients than in those individuals with $\mathrm{CP}$. There was no detectable parasite-specific spots observed among normal North American control individuals for either the IgE or IgG assay ( $n=5$, data not shown).

The serum antibody levels of parasite-specific IgE and IgG were correlated with the frequency of antigen-specific B lymphocytes found in the PBMC (IgE, $r=0.88, P<0.001$; IgG, $r$ $=0.6, P<0.001$; Fig. 5).

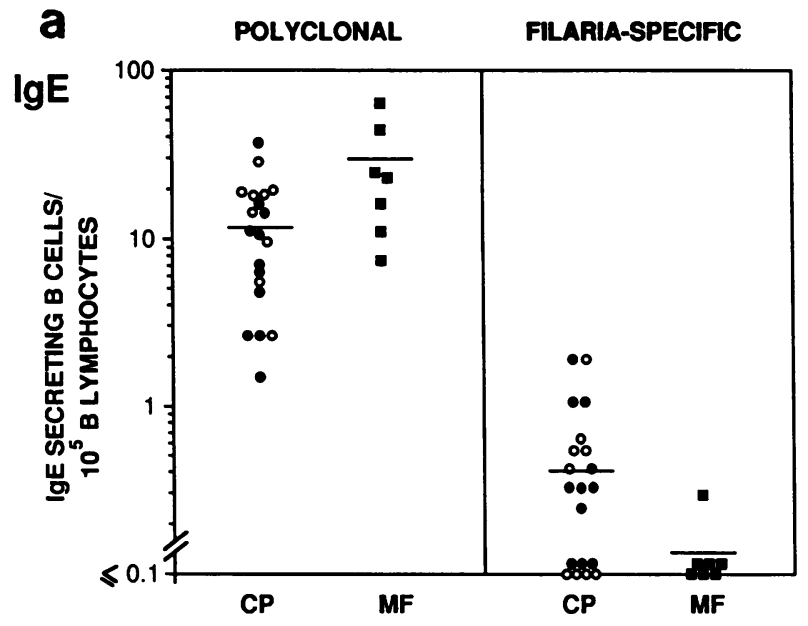

b

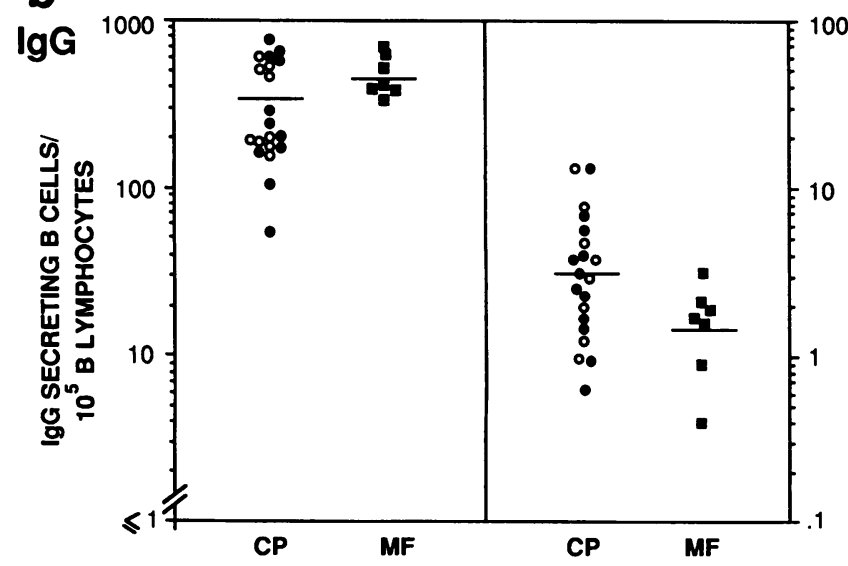

Figure 3. The frequency of polyclonal and parasite-specific IgE- $(a)$ and IgG- $(b)$ secreting cells in PBMC from patients with CP or MF. Each data point represents a single individual. Horizontal lines indicate geometric means. Note the different scales for total and filarial-specific IgG.
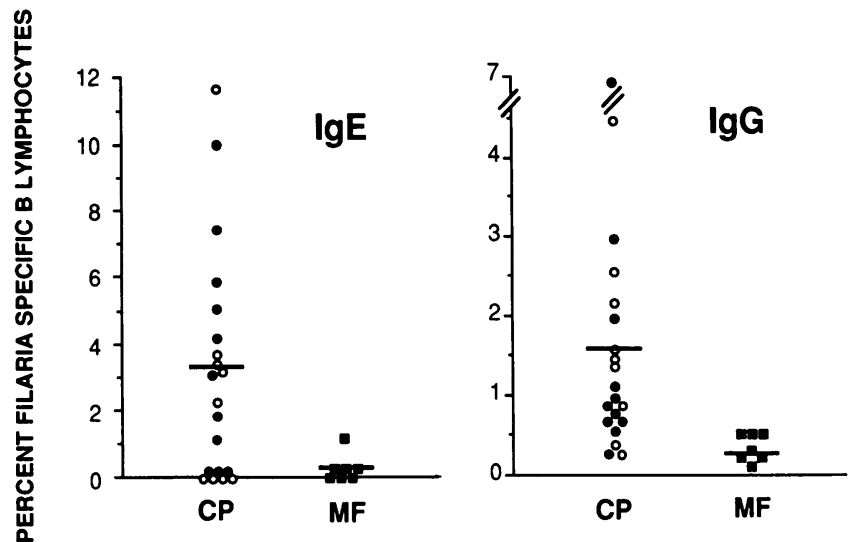

Figure 4. The percentage of B lymphocytes secreting antifilarial IgE or IgG antibodies in patients with lymphatic filariasis. Each point represents an individual patient. Horizontal lines indicate arithmetic means.

\section{Discussion}

Selectively impaired $\mathrm{T}$ and $\mathrm{B}$ cell responses to filarial parasite antigens have been well documented among patients with the microfilaremic form of infection with the filarial parasites $\mathrm{Wu}$ chereria bancrofti and B. malayi. The altered T cell responsiveness has been observed as diminished delayed-type hypersensitivity responses to intradermal application of filarial antigens (20), and as markedly reduced T lymphocyte proliferation responses to parasite antigens in vitro, but not to nonparasite antigens $(4,9,10,21)$. The specific $B$ cell deficits in these microfilaremic patients are reflected both in low serum levels of parasite-specific antibodies $(3,6,22)$ and in impaired immunoglobulin production by PBMC in response to parasite antigens in vitro (7). The mechanisms underlying this apparent immunological hyporeactivity in microfilaremic patients remain poorly defined; although previous studies in patients with $B$. malayi infection have suggested active suppression by either monocytes (9) or suppressor T lymphocytes (10). Similar studies with PBMC from patients with $W$. bancrofti have failed to identify such suppressor cell populations $(7,8)$. Furthermore, the fact that PBMCs from microfilaremic patients with bancroftian filariasis failed to produce parasite-specific antibody in response to parasite antigen or pokeweed mitogen (7) has suggested the possibility that the absence of antigen-responsive lymphocytes could be responsible for the diminished response by microfilaremic patients.

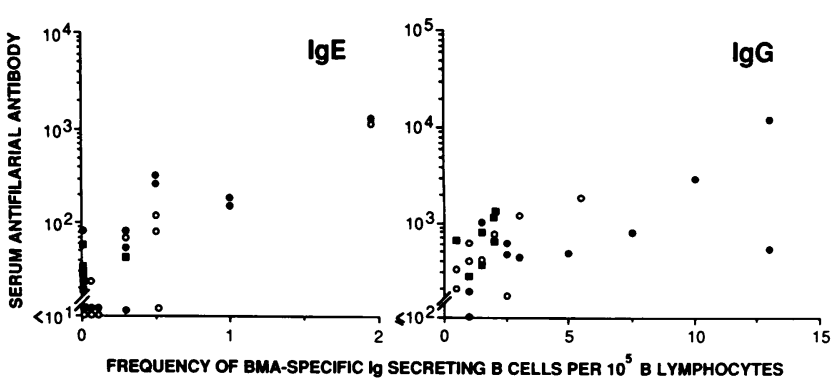

Figure 5. The correlation between the number of filaria-specific IgE or IgG-secreting B cells per $10^{5}$ B lymphocytes and serum antifilarial antibody levels. As described in the legend for Fig. 2, each data point represents either an MF patient (square) or CP patient (circle). 
Indeed, our present study shows direct evidence for a decreased frequency of parasite antigen reactive $T$ and $B$ lymphocytes in microfilaremic individuals compared with the amicrofilaremic patients; fewer than 1 in 3,757 T cells of the microfilaremic patients responded to parasite antigen in a limiting dilution analysis (a figure approaching that of normal, unexposed individuals [Fig. 2]), whereas 2.5 times as many antigenspecific $T$ lymphocytes ( 1 in 1,513 ) were observed among symptomatic amicrofilaremic individuals. However, by activating $\mathrm{T}$ cells in limiting dilution, we observed that with decreasing concentrations of $\mathrm{T}$ cells, the decrease in the fraction of positive cultures was less than expected in cultures with low $\mathrm{T}$ cell numbers if a single cell type was limiting (e.g., a single hit phenomenon). This nonlinear relationship between $T$ cells in limiting dilution and the fraction of positive cultures has been increasingly observed, especially when $T$ cell concentrations are examined over a broader range in response to heterogenous antigens. These types of findings are felt to result from multiple limiting populations of interacting $T$ cells $(23,24)$. Our results are consistent with the concept of several populations of antigen-reactive $T$ cells and suggest the presence of both modulating and proliferating $T$ cells responding to the parasite antigens. In particular, these modulating (or regulatory) cells appear to be fewer in number than the proliferating cells, and in cultures with few T lymphocytes, few or no suppressor cells would be present. Proliferating cells (at least in terms of generating lymphocyte proliferation) would thus be predominant. A model of crossregulating Th (CD4+) subsets has been described in the mouse $(25,26)$, and appears to exist in humans (27). This model might explain, in part, the effect observed in our studies. CD4+ cells that produce the cytokines IL-2 and IFN- $\gamma$ (Th1 subset) are likely the principal reactive cells in limiting dilution analysis because IL-2 drives lymphocyte proliferation responses. In contrast, CD4+ cells that produce IL-4 and IL-5 (Th2 subset) do not proliferate to the extent of Th1 cells and further, they generate other cytokines, in particular IL-10, that can inhibit proliferation and cytokine secretion by Th1 cells.

We have recently developed a filter immunoplaque assay capable of measuring individual parasite antigen-reactive IL-4 or IFN- $\gamma$-secreting CD4+ cells in human peripheral blood (28). Using this technique, our preliminary results indicate the presence of parasite antigen-reactive $\mathrm{Th} 1$ and $\mathrm{Th} 2$ subpopulations in PBMC from individuals residing in the same $W$. bancrofti endemic area with similar clinical findings. Furthermore, the ratio of Th2 to Th1 lymphocytes was higher in MF compared with $\mathrm{CP}$ patients (unpublished observations). These results are compatible with the hypothesis that the specific immune unresponsiveness observed in bancroftian filariasis results from a state of parasite-specific anergy induced, in part, by specific cytokines from a subpopulation of antigen-reactive $\mathrm{T}$ lymphocytes.

A weighted regression analysis was used to estimate the frequency of antigen-reactive lymphocytes in this study instead of the more conventional methods $(14,15)$ that assume a linear relationship between the concentration of $T$ cells and the (log) fraction of negative cultures. The estimated frequencies of antigen-reactive cells were much higher (e.g., $\mathrm{GM}=1 / 1,513$ for $\mathrm{CP}$ and $\mathrm{GM}=1 / 3,757$ for $\mathrm{MF}$ ) compared with those estimated by conventional LDA (GM = 1/7,200 for $\mathrm{CP}$ and $\mathrm{GM}=1 / 73,000$ for MF; data not shown). However, there was a close correlation between the two estimates $(r=0.76, P<0.001$ for $\mathrm{CP}$ patients and $r=0.93, P<0.001$ for MF), indicating that al- though the estimated frequencies are different, the relationship (MF have significantly fewer antigen-reactive cells than CP) remains the same. More importantly, however, estimates using an independent estimate of frequencies of antigen reactive cells, that being the number of IFN- $\gamma$-producing lymphocytes determined by a filter-immunoplaque assay (28), showed that numbers of IFN- $\gamma$-producing lymphocytes from individuals from the same endemic foci were strikingly similar to those found using the weighted regression analysis (for CP patients, $\mathrm{GM}=1 / 1,480 ; n=10$, data not shown). Clearly a direct comparison cannot be made between these two methods because they were performed on different individuals from a small sample. They do show, however, that the estimates of cell frequencies based on the limiting dilution data approximate those obtained by a completely independent method.

The frequency of parasite-specific B lymphocytes was also seen to be reduced significantly among microfilaremic individuals. Parasite-specific IgE-secreting cells were detectable in only 1 of 7 (14\%) microfilaremic patients in contrast to 13 of 20 (65\%) symptomatic amicrofilaremic patients, even though the frequency of polyclonal IgE-secreting cells tended to be higher among the microfilaremic patients (Fig. 3). In addition, the proportion of parasite-specific IgG-secreting cells was sixfold lower $(0.3 \%)$ among MF patients compared with the amicrofilaremic, CP individuals (1.8\%). This low frequency of parasite-specific $B$ cells among microfilaremic individuals most likely reflects the diminished number of parasite antigen-reactive T lymphocytes.

The basis for determining differences in B cell precursor frequencies among MF and CP individuals derives from a filarial antigen-specific ELISPOT assay that is presented for the first time. The assay showed no nonspecific binding by IgE or IgG secreted by cells from either normal North Americans ( $n$ $=5$ ), an IgE myeloma cell line (U266), or PBMC from an hyper-IgE individual. There may be, however, limitations in the sensitivity of assay because of the antigenic mixture used for coating the wells. For example, if a particular antigen containing a B cell epitope were at relatively low concentrations in antigenic mixture, bound antibody might be insufficient to be detectable in the assay. However, coating the nitrocellulose plate with increased quantities of coating antigen (20 and 50 $\mu \mathrm{g} / \mathrm{ml}$ ) failed to detect additional filarial-specific B cells in two MF patients so studied (data not shown). Studies using purified stage-specific antigens would be preferable; the lack of such antigens has hampered this approach.

Although previous studies $(6,8,21)$ have shown significantly reduced serum antifilarial antibody levels in asymptomatic MF patients compared with those with $\mathrm{CP}$, this study failed to show such a difference when group means were compared. Nevertheless, there was a significantly lower frequency of filarial antigen-specific $B$ cells in MF patients compared with $\mathrm{CP}$ individuals (the frequencies in turn correlating with serum filarial-specific IgE and IgG levels [Fig. 5]). The failure to detect a significant difference in serum antifilarial antibody levels between the two groups reflects the extreme variability of antibody levels among the $\mathrm{CP}$ patients that has likely resulted from prolonged treatment with antifilarial drugs. In fact, some individuals may no longer have active filarial infections. To address this issue more directly, circulating parasite antigens rich in phosphocholine moieties were measured in all individuals. There was, however, no correlation between circulating antigen levels and their $\mathrm{B}$ or $\mathrm{T}$ cell responses. That some $\mathrm{CP}$ individ- 
uals may have inactive filarial infections at the time of study would be reflected more often in variable serum IgE levels (rather than IgG), as the half-life IgE is about $25 \%$ that of $\mathrm{IgG}$.

The basis for the low frequency of parasite-specific lymphocytes among microfilaremic individuals has been postulated to result from in utero or perinatal sensitization to parasite antigens or to anti-idiotype antibodies. Indirect evidence for possible prenatal sensitization has come from findings that anti-filarial antibodies of isotypes that do not cross the placenta (e.g., IgE and IgM) can be identified in the cord blood of babies born to infected mothers (29), or in the cord sera of several babies born in a region endemic for $W$. bancrofti (30). Under these circumstances, exposure of immature $T$ and $B$ cells in the fetal or newborn thymus to filarial antigens or anti-idiotypic antibodies may result in deletion of an antigen-responsive $T$ cell clone (clonal deletion), or more likely, as our evidence suggests, the generation of a subpopulation of antigen-reactive lymphocytes involved in a network of active crossregulation (31).

Epidemiologic evidence also supports the notion that exposure to filarial parasites during early development may be of critical importance in determining an individual's subsequent response to filarial infection; i.e., whether he develops symptomatic, inflammatory pathology or asymptomatic microfilaremia. Among thousands of previously unexposed American serviceman stationed in heavily endemic areas of the South Pacific during World War II, fully one third of those exposed became infected and symptomatic, yet less than 1 in 1,000 developed microfilaremia. In contrast, microfilaremia rates in local populations reached $30-50 \%$ with clinical pathology rates of about $5-10 \%$ (32). More recently, similar observations were made among transmigrant Indonesians who, as part of a government-sponsored relocation program, were moved from filaria-nonendemic to filaria-endemic areas $(33,34)$.

Another mechanism of specific unresponsiveness observed among microfilaremic individuals could be that of peripheral tolerance through exposure later in life. Peripheral tolerance implies that a state of proliferative unresponsiveness is caused by an absence of a costimulatory signal from the antigen-presenting cell. It is possible that acquisition of infection in childhood may allow for the microfilaremic state to be established. This, in turn, leads to a high intravascular antigen load that either "saturates" or fails to engage the appropriate subsets of antigen-presenting cells that would be responsible to deliver the appropriate costimulatory signal (35). Although states of immune unresponsiveness have been described in other helminth infections (e.g., schistosomiasis [36], onchocerciasis [37]), several protozoal infections (e.g., visceral leishmaniasis [38], malaria [39]), and the lepromatous form of the mycobacterial disease leprosy (40), only one study has attempted a quantification of antigen-specific $\mathrm{T}$ cells among the unresponsive individuals (41). In that study of eight patients with leprosy (four tuberculoid, four lepromatous), the frequencies of $\mathrm{T}$ cells responsive to mycobacterial antigens were significantly lower in lepromatous patients $(1 / 13,679-1 / 73,422)$ than in individuals with tuberculoid disease $(1 / 3,656-1 / 10,906)$. Although these findings parallel those made in our study, there are at least two important differences between the two studies. First, the limiting dilution studies in leprosy patients used unfractionated PBMC, allowing the possibility that monocytes may be actively suppressing the proliferation among $T$ cells from lepromatous patients. Second, unlike bancroftian filariasis, the immunosuppression in lepromatous leprosy is generalized (40) and may result from nonspecific immunosuppression by mycobacterial antigens (42).

While the results of our present study using the techniques of limiting dilution analysis and direct filter-spot ELISAs to investigate differences in parasite-specific lymphocyte responses among patients with different clinical manifestations of filariasis suggests that a state of tolerance, possibly through a network of active crossregulation, may be the mechanism involved in maintaining the microfilaremic state, further studies are required to identify the nature of these regulatory cells. We have hypothesized antigen-reactive $\mathrm{Th} 2$ cells could contribute to this suppression through production of crossregulatory cytokines such as IL-10 or TGF- $\beta$. To evaluate this hypothesis further, the relative frequencies of antigen-reactive Th2 lymphocytes could be more completely determined among MF patients compared with symptomatic amicrofilaremic individuals with bancroftian filariasis, and the roles of IL-10 and TGF$\beta$ assessed by either measuring their levels directly in $T$ cell cultures or by the addition of specific neutralizing antibodies. Such studies are currently underway. Similarly, since chemotherapy has been demonstrated to restore (i.e. release from the tolerant state) proliferative responses of unfractionated PBMC in patients with microfilaremia $(43,44)$, changes in cytokine profiles or specific CD4+ cell populations could be examined before and after treatment. Through the use of these approaches, the regulatory aspects of the immune responses to parasites and parasite antigens should be able to be dissected with increasing precision and detail so that possible targets can eventually be identified for modulating the host response and, thus, the nature of the disease in patients with filarial infections.

\section{References}

1. Filariasis. 1984. Fourth Report World Health Organization Technical Report. Serial No. 702.

2. Ottesen, E. A. 1980. Immunopathology of lymphatic filariasis in man. Springer Semin. Immunopathol. 2:373-385.

3. Ottesen, E. A., P. F. Weller, M. Lunde, and R. Hussain. 1982. Endemic filariasis on a Pacific Island. II. Immunological aspects: immunoglobulin, complement, and specific antifilarial IgG, IgM and IgE antibodies. Am. J. Trop. Med. Hyg. 31:953-961.

4. Ottesen, E. A., P. F. Weller, and L. Heck. 1977. Specific cellular immune unresponsiveness in human filariasis. Immunology. 33:413-421.

5. Piessens, W. F., P. B. McGreevy, P. W. Piessens, M. McGreevy, J. Koiman, H. S. Saroso, and D. T. Dennis. 1980. Immune responses in human infections with Brugia malayi. Specific cellular unresponsiveness to filarial antigens. J. Clin. Invest. 65:172-179.

6. Hussain, R., R. G. Hamilton, V. Kumaraswami, N. F. Adkinson, and E. A. Ottesen. 1981. IgE response in human filariasis. I. Quantitation of filaria-specific IgE. J. Immunol. 127:1623-1629.

7. Nutman, T. B., V. Kumaraswami, L. Pao, P. R. Narayanan, and E. A. Ottesen. 1987. An analysis of in vitro B cell immune responsiveness in human lymphatic filariasis. J. Immunol. 138:3954-3959.

8. Nutman, T. B., V. Kumaraswami, and E. A. Ottesen. 1987. Parasite-specific anergy in human filariasis. Insights after analysis of parasite antigen-driven lymphokine production. J. Clin. Invest. 79:1516-1523.

9. Piessens, W. F., S. Ratiwaytano, S. Tuti, J. H. Palmieri, P. W. Piessens, J. Koiman, and D. T. Dennis. 1980. Antigen-specific suppressor cells and suppressor factors in human filariasis with Brugia malayi. N. Engl. J. Med. 302:833-837.

10. Piessens, W. F., F. Partono, S. L. Hoffman, S. Ratiwayanto, P. W. Piessens, J. R. Palmieri, J. Koiman, D. T. Dennis, and W. P. Carney. 1982. Antigenspecific suppressor T lymphocytes in human lymphatic filariasis. N. Engl. J. Med. 307:144-148.

11. Weller, P. F., and E. A. Ottesen. 1978. Failure of diethylcarbamazine as a provocative test in subperiodic Wuchereria bancrofti filariasis. Trans. $R$. Soc. Trop. Med. Hyg. 7:31-32.

12. Boyum, A. 1968. Separation of leukocytes from blood and bone marrow. Scand. J. Clin. Lab. Invest. 21(Suppl. 97):77-89. 
13. Macy, E., M. Kemeny, and A. Saxon. 1988. Enchanced ELISA: how to measure less than 10 picograms of a specific protein (immunoglobulin) in less than 8h. FASEB (Fed. Am. Soc. Exp. Biol.) J. 2:3003-3006.

14. King, C. L., G. Thyphronitis, and T. B. Nutman. 1990. Enumeration of IgE secreting B cells. A filter spot-ELISA. J. Immunol. Methods. 132:37-43.

15. King, C. L., R. W. Poindexter, J. Ragunathan, T. A. Fleisher, E. A. Ottesen, and T. B. Nutman. 1991. Frequency analysis of IgE-secreting B lymphocytes in persons with normal or elevated serum IgE levels. J. Immunol. 146:1478-1483.

16. Smedman, L., M. Troye-Blomberg, H. Perlmann, A. Naucler, and P. Perlmann. 1989. Phenotypic characterization of mononuclear white cells using finger-prick blood and light microscopy. Am. J. Trop. Med. Hyg. 41:116-121.

17. Alling, D. W. 1971. Estimation of hit number. Biometrics. 27:605-613.

18. Lefkovitz, I., and H. Waldman. Limiting Dilution Analysis of Cells in the Immune System. Cambridge University Press, Cambridge, England. 1979:257.

19. Taswell, C. 1981. Limiting dilution assays for the determinations of immunocompetent cell frequencies. I. Data analysis. J. Immunol. 126:1614-1619.

20. Weller, P. F., E. A. Ottesen, and L. Heck. 1980. Immediate and delayed hypersensitivity skin test responses to the Dirofilaria immitis filarial skin test (Sawada) antigen in Wuchereria bancrofti filariasis. Am. J. Trop. Med. Hyg. 29:809-814.

21. Piessens, W. F., P. B. McGreevy, P. W. Piessens, M. McGreevy, J. Koiman, H. S. Saroso, and D. T. Dennis. 1980. Immune responses in human infections with Brugia malayi. Specific cellular unresponsiveness to filarial antigens. $J$. Clin. Invest. 65:172-179.

22. McGreevy, P. B., S. Ratiwayanto, S. Tuti, M. M. McGreevy, and D. T. Dennis. 1980. Brugia malayi: Relationship between anti-sheath antibodies and amicrofilaremia in natives living in an endemic area of South Kalmantan, Borneo. Am. J. Trop. Med. Hyg. 29:553-562.

23. Melchers, I., K. Fey, and K. Eichmann. 1982. Quantitative studies in T cell diversity. III. Limiting dilution analysis of precursor cells for $\mathrm{T}$ helper cells reactive to xenogeneic erythrocytes. J. Exp. Med. 156:1587-1603.

24. Fey, K., I. Melchers, and K. Eichmann. 1983. Quantitative studies on T cell diversity IV. Mathematical analysis of multiple limiting populations of effector and suppressor T cells. J. Exp. Med. 158:40-52.

25. Mosmann, T. R., H. Cherwinski, M. A. Bond, I. Giedlin, and R. L. Coffman. 1986. Two types of murine helper T cell clones. I. Definition according to the profiles of lymphokine activities and secreted proteins. J. Immunol. 136:2348-2354.

26. Mosmann, T. R., and K. W. Moore. 1991. The role of IL-10 in crossregulation of $\mathrm{Th} 1$ and $\mathrm{Th} 2$ responses. Immunol. Today. 12:49-53.

27. Del Prete, G. F., M. De Carli, C. Mastromauro, D. Macchia, P. Falagiani, N. Ricei, and S. Romagnani. 1991. Purified protein derivative of Mycobacterium tuberculosis and excretory-secretory antigen(s) of Toxocara canis expand in vitro human $\mathrm{T}$ cell with stable and opposite (Type $1 \mathrm{~T}$ helper or Type $2 \mathrm{~T}$ helper) profile of cytokine production. J. Clin. Invest. 88:346-350.

28. Mahanty, S., J. S. Abrams, A. P. Limaye, C. L. King, and T. B. Nutman. 1991. Parallel regulation of IL-4 and IL-5 in human helminth infections. Clin. Res. 39:304A.
29. Weil, G. J., R. Hussain, V. Kumaraswami, S. P. Tripathy, K. S. Phillips, and E. A. Ottesen. 1983. Prenatal allergic sensitization to helminth antigens in offspring of parasite-infected mothers. J. Clin. Invest. 71:1124-1129.

30. Sanjeevi, C. B., and P. R. Narayanan. 1989. Antifilarial and anti PPD IgM antibodies in cord blood. Indian J. Pediatr. 56:207-211.

31. Nossal, G. J. V. 1990. Immunologic tolerance: collaboration between antigen and lymphokines. Science (Wash. DC). 245:147-153.

32. Wartman, W. B. 1947. Filariasis in American armed forces in World War II. Medicine (Baltimore). 26:333-394.

33. Partono, R., S. Oemijati, J. A. Hudojo, H. Sajidiman, J. Putrali, N. D. Clark, W. P. Carney, and J. H. Cross. 1977. Malayan filariasis in Central Sulawesi (Celebes). Indonesia. Southeast Asian J. Trop. Med. Public Health. 8:452.

34. Partono, F., W. Purnomo, A. Pribadi, and Soewarta. 1978. Epidemiological and clinical features of Brugia timori in a newly established village, Karakuak, West Flores, Indonesia. Am. J. Trop. Med. Hyg. 27:910.

35. Matzinger, P., and S. Guerder. 1989. Does T-cell tolerance require a dedicated antigen-presenting cell? Nature (Lond.). 338:74-76.

36. Ottesen, E. A. 1979. Modulation of the host response in human schistosomiasis. I. Adherent suppressor cells that inhibit lymphocyte proliferative responses to parasite antigens. J. Immunol. 123:1639-1644.

37. Gallin, M., K. Edmonds, J. J. Ellner, K. D. Erttman, A. T. White, H. S. Newland, H. R. Taylor, and B. M. Greene. 1988. Cell-mediated immune responses in human infection with Onchocerca volvulus. J. Immunol. 140:19992007.

38. Carvalho, E. M., O. Bacellar, A. Barra, R. Badaro, and W. D. Johnson. 1989. Antigen-specific immunosuppression in visceral leishmaniasis is cell mediated. J. Clin. Invest. 83:860-864.

39. Ojo-amaize, E. A., L. S. Salimonu, A. I. O. Williams, O. A. O. Akinwolere, R. Shabo, G. V. Alm, and H. Wizzell. 1981. Positive correlation between the degree of parasitemia, interferon titers, and natural killer cell activity in Plasmodium falciparum-infected children. J. Immunol. 127:2296-3000.

40. Kaplan, G., D. E. Weinstein, R. M. Steinman, W. R. Levid, U. Elvers, M. E. Patarroyo, and Z. A. Cohn. 1985. An analysis of in vitro T cell responsiveness in lepromatous leprosy. J. Exp. Med. 162:917-929.

41. Brett, S. J., A. E. Kingston, and M. J. Colston. 1987. Limiting dilution analysis of the human $T$ cell response to mycobacterial antigens from BCG vaccinated individuals and leprosy patients. Clin. Exp. Immunol. 68:510-520.

42. Kaplan, G., R. R. Gandhi, D. E. Weinstein, W. R. Lewis, M. E. Patarroyo, P. J. Brennan, and Z. A. Cohn. 1987. Mycobacterium leprae antigen-induced suppression of T cell proliferation in vitro. J. Immunol. 138:3028-3034.

43. Lammie, P. J., M. L. Eberhard, L. E. Leiva, R. C. Lowrie, and S. P. Katz. 1988. Bancroftian filariasis in Haiti: preliminary characterization of the immuno logical responsiveness of microfilaremic individuals. Trans. $R$. Soc. Trop. Med. Hyg. 82:726-729.

44. Piessens, W. F., S. Tratiwayanto, P. W. Piessens, S. Tuti, P. B. McGreevy, F. Darwis, J. R. Palmieri, J. Koiman, and D. T. Dennis. 1981. Effect of treatment with diethylcarbamazine on immune responses to filarial antigens in patients infected with Brugia malayi. Acta Trop. 38:227-234. 